\title{
LA ESENCIA DEL AMOR EN KIERKEGAARD. INTERPRETACIÓN DE LAS OBRAS DEL AMOR (1847)
}

FRANCESC TORRALBA

Universitat Ramon Llull

\begin{abstract}
RESUMEN: el objeto formal de este artículo es la noción de amor que está latente en la obra de Søren Kierkegaard, Las obras del amor (1847). Este texto que, por razones muy distintas, ha sido ignorado por la crítica especializada, presenta con nitidez la concepción que tenía el pensador danés del amor en la etapa madura de su pensamiento. Se analiza el fundamento, las cualidades y las manifestaciones del amor tal y como los concibe Søren Kierkegaard.
\end{abstract}

PALABRAS CLAVE: amor, Dios, eternidad.

\section{The essence of love in Kierkegaard. Interpretation of Works of love (1847)}

ABSTRACT: the goal of this article is to explore the notion of love present in Søren Kierkegaard's The works of Love. For several reasons, this work has been ignored among the critical commentators of Kierkegaard. The author clarifies the foundations, the qualities and the expressions of the love according to Søren Kierkegaard's philosophy.

KEY WORDS: love, God, eternity.

\section{ENSAYO DE INTERPRETACIÓN}

La época en la que apareció Las obras del amor (1847) (Kjerlighed Gjerninger) fue muy fecunda en la vida de Søren Kierkegaard. Sabemos, por una anotación en los Papirer, que el 2 de agosto de 1847 ya había terminado el manuscrito. Durante el año 1846 había publicado el Postscriptum (Afsluttende uvidenskabelig Efterskrift ${ }^{1}$, Una recensión literaria (En literair Anmeldelse) ${ }^{2}$, y pocos meses antes, los Discursos edificantes en distintos espiritus (Opbyggelige Taler i forskjellig Aand) ${ }^{3}$.

El 29 de septiembre de 1847, Las obras del amor ya estaba en las librerías de Copenhague. Es significativo remarcar que en la audiencia que el rey de Dinamarca concedió a Kierkegaard el año de la publicación del texto, el filósofo danés leyó al monarca el capítulo titulado El amor es un asunto de conciencia y anota en los Papirer que el rey se emocionó con la lectura ${ }^{4}$.

Kierkegaard escribe: «Estas meditaciones cristianas, que son fruto de mucha deliberación, querrían ser comprendidas con lentitud, para serlo también con facilidad, mientras que probablemente resultarán muy difíciles para quienes con una lectura superficial y curiosa, las haga muy difíciles $»^{5}$.

1 Esta obra fue publicada bajo el seudónimo de Johannes Climacus el 27 de febrero de 1846.

La publicó el 30 de marzo de 1846.

3 Estos discursos fueron publicados el 13 de marzo de 1847.

4 Cf. Pap., X 1 A 42.

5 Las obras del amor. Meditaciones cristianas en forma de discursos, Sígueme, Salamanca, 2006, p. 17.

Cito, también, la edición danesa: Søren Kierkegaards Skrifter Elektronisk versión 1.4. El título original de la obra és Kjerlighedens Gjerninger. Nogle christelige Overveielser i Talers Form. Se cita KG, número de 
Con la pátina irónica que caracteriza la prosa kierkegaardiana, el autor introduce una condición de posibilidad, nada menor, para comprender Las obras del amor: la lentitud. Esta obra no fue escrita para ser leída aceleradamente, sino para ser meditada, releída, de una forma circular. Se propone un efecto distinto que, habitualmente, se plantea cuando elabora un texto filosófico. Su finalidad es conmover al lector, suscitarle la escucha de una llamada, una metamorfosis que altere su estilo de vida.

El destinatario del texto es el individuo singular (den Enkelte). Kierkegaard no se propone hacer una filosofía in abstracto, sino una meditación orientada directamente a cada lector, con la finalidad de transformar su corazón, de suscitar en él una conversión. El objetivo no es solo que piense, sino que se pregunte qué cree y por qué cree lo que cree. En este sentido, huye intencionalmente del lenguaje abstruso y conceptual, y opta por una comunicación directa, aparentemente sencilla, sin filtros, ni seudónimos, mediante una forma de comunicación que él mismo denomina «comunicación de existencia».

Las obras del amor pertenece al género literario de los Discursos (Taler). En ellos prevalece la manifestación personal, el tono exhortativo y confidencial, la belleza plástica de las imágenes y la sensibilidad poética. Estas características son suficientes para situar los Discursos en la parte lírica de la obra del filósofo danés. El estilo literario y la forma es radicalmente distinta del estilo de las obras seudónimas.

Aunque los Discursos son eminentemente líricos, de ahí no se deriva que estén vacíos desde el punto de vista filosófico. Más bien al contrario. En ellos se plantean cuestiones radicales de la existencia y se debaten graves problemas de la vida humana; pero el modus operandi no es tan solo dialéctico, sino expositivo e interpretativo. El eje central es el Evangelio y Søren Kierkegaard comenta libremente determinadas perícopas que se convierten en un pretexto para exponer sus propias ideas en materia antropológica, teológica y filosófica.

En los Discursos, Kierkegaard dialoga consigo mismo. Se podrían definir como el precipitado intelectual de lo que don Miguel de Unamuno, su hermano gemelo hispánico, denomina autodiálogo ${ }^{6}$. En los Discursos plasma sus dudas, sus meditaciones, expone sus certezas. No trata de verificarlas ni dotar de una solidez metafísica a sus afirmaciones. A pesar de ello, hay un uso de la racionalidad, una forma de argumentar y de razonar que tiene un fuerte potencial persuasivo. Subrayamos este elemento, porque, con demasiada frecuencia, se han relegado los Discursos a puras expresiones emocionales o de piedad.

La temática de los Discursos es, en esencia, religiosa; más en concreto, cristiana. El autor parte de un fragmento del Antiguo o del Nuevo Testamento y lo comenta desde su prisma subjetivo. No existe ninguna referencia a la tradición de la Iglesia, ni a ningún pensador. $\mathrm{O}$ al menos, explícita. No se propone hacer una exégesis bíblica, ni trata de explorar las fuentes que alimentan y posibilitan el texto. Se limita a comentarlo libremente y a sacar conclusiones para la vida práctica.

El Discurso posee una lógica muy determinada. El autor empieza describiendo las palabras del profeta o del apóstol, aclarando su sentido y finalidad. Posteriormente divaga sobre un punto determinado del texto en cuestión. Repite aquella frase que ha cautivado su corazón, potenciando, de esta forma la meditatio cordis en el lector. Reflexiona a partir de cada palabra que articula la frase. Un ejemplo evidente lo encontramos,

la página en números árabes. «Disse christelige Overveielser, som ere Frugten af megen Overveielse, ville forstaaes langsomt men da ogsaa let, medens de vistnok ville blive meget vanskelige, om Nogen ved flygtig og nysgjerrig Læsning gjør sig dem meget vanskelige» (KG 11). Se puede buscar la versión electrónica en: http: //sks.dk/forside/skk.asp.

6 Cf. Unamuno, M. DE, Soledad, Espasa Calpe, Madrid, 1970. 
precisamente, en Las obras del amor. Centra la atención en la frase: «Tienes que amar a tu prójimo» y para sacar todo su contenido, discurre sobre el sujeto $(D u)$, sobre el deber de amar (elsker) y sobre la noción de prójimo (Naesten).

Casi todos los Discursos están dedicados a la memoria de su padre, Michael Pedersen. Esta evocación es un signo de gratitud hacia su progenitor, que le introdujo en la fe cristiana. Kierkegaard distingue con nitidez el Discurso del sermón. Según él, el sermón es un texto elaborado por un pastor, por un hombre que ha recibido el ministerio de la Palabra y ello le confiere autoridad. El autor del Discurso, en cambio, es un hombre corriente, un cristiano común que medita el texto y expone sus meditaciones. Por ello está faltado de autoridad, es un texto subjetivo y exhortativo.

Contrariamente a lo que pensaba Hegel, Kierkegaard considera que la finalidad de la filosofía es la edificación. Su pretensión no es convertir la filosofía en ciencia (Wissenschaft) ni tratar de dotarla de un estatuto epistemológico parecido al de las ciencias experimentales o deductivas. Entiende la filosofía como una actividad, como una tarea cuya finalidad es hacer pensar, orientar en la existencia, edificar el espíritu. En los Discursos, el filósofo danés mantiene una polémica contra la especulación teorética. Tienen una orientación práctica, la creación de una sabiduría de la vida, de una orientación en la existencia.

Los Discursos y también Las obras del amor, son textos para ser leídos en voz alta. No en balde, el texto contiene una serie de elementos muy propios de la comunicación oral: las reiteraciones, las imágenes poéticas, los ejemplos vivos, las exclamaciones, los vocativos. Toda esta constelación de caracteres tiene como finalidad cautivar la atención del oyente de tal manera que penetre dentro de la atmósfera cristiana. Él mismo pronunció algunos de los Discursos en iglesias de Copenhague. Son, por tanto, para ser escuchados en un lugar sagrado.

Los Discursos constituyen una pieza clave en la obra kierkegaardiana. Desde el 16 de mayo de 1843 hasta el 7 de agosto de 1851 el pensador danés publicó, casi de forma ininterrumpida, un total de noventa Discursos. La aparición de estos textos es simultánea a la publicación de las obras seudónimas, aunque ninguno de sus coetáneos, a excepción del editor, imaginó que ambas producciones fueran creadas por el mismo autor ${ }^{7}$.

Más allá de la atención prioritaria que han merecido por la crítica las obras seudónimas, en el conjunto de su producción intelectual, los Discursos gozan de una relevancia más notoria que las obras seudónimas. Están todos firmados de su puño y letra como es el caso, también de Las obras del amor. Después de los Diarios (Papirer A, B, C) los Discursos constituyen la parte más genuinamente kierkegaardiana de todo el complejo entramado de su producción.

Las obras del amor es una monografía que se estructura en dos partes precedidas por una oración. Cada parte va, a la vez, precedida por un prólogo. En la primera parte, el filósofo danés explora la vida oculta del amor, el deber de amar al prójimo y la naturaleza del amor, mientras que, en la segunda, investiga los frutos del amor, sus obras. Tal como lo describe, el amor es la fuente de la edificación, de la esperanza y de la fe.

\footnotetext{
7 Existen muchos ejemplos de esta simultaneidad a lo largo de su vida. Durante el 1843 por ejemplo, Kierkegaard publicó Enten Eller ( $O$ esto o aquello) bajo el seudónimo Victor Eremita, Gjentagelsen (La repetición) con el seudónimo Constantin Constantius, Frygt og Baven (Temor y temblor) de Johannes de Silentio, pero el mismo año publicó To opbyggelige Taler (Dos discursos edificantes), el 16 de mayo de 1843; Tre opbyggelige Taler (Tres discursos edificantes), el 16 de octubre de 1843, Fire opbyggelige Taler (Cinco discursos edificantes), el 6 de diciembre de 1843.
} 
En la oración, Kierkegaard exalta el amor de Dios, al que considera la raíz de todo amor y su fuerza motriz. Tal y como la concibe, la oración es un juego de lenguaje muy particular, un diálogo entre el individuo singular (Enkelte) y Dios (Gud), pero, especialmente un acto de escucha. Dios crea la individualidad, pero la hace subsistir eternamente como tal.

El diálogo es posible porque hay dualidad, pero no una dualidad simétrica, sino esencialmente asimétrica. Con todo, Dios, por amor, transciende la distancia infinita cualitativa que lo separa del hombre, para revelarse en su corazón. Respeta a la criatura humana y escucha su clamor. Para hacer realidad esta unión íntima, es esencial que el hombre ensanche la escucha del espíritu, aquella que le permite ser receptivo a la Palabra de Dios (Guds Ordet).

\section{Fundamentos DEL AMOR}

En las primeras páginas de esta magna obra, el filósofo danés se pregunta por la procedencia y por el origen del amor. Según Kierkegaard, el amor procede del estrato más oculto del ser humano, de un lugar secreto y misterioso, enigmático, de lo más íntimo que hay en su interior, entendido a la forma agustiniana. Nace del fondo del ser humano, pero no es patrimonio ni propiedad del ser humano, porque tiene un origen no humano. El amor procede del interior, pero no es generado por el ser humano. Lo transciende, tanto por lo que concierne a sus génesis como por lo que respecta a su destino.

Brota de las profundidades del ser y se expresa de múltiples formas, por innumerables vetas, aunque ninguna conduce a la Fuente originaria, a saber, Dios. Kierkegaard desconoce la categoría metafísica de analogía del ente (analogía entis), pero admite que el amor se dice de muchas formas y a la vez reconoce que solamente a través de sus frutos, las obras (Gjerninger), podemos explorar su esencia, lo que siempre escapa a las fronteras de la razón, por expresarlo en la forma kantiana.

Reconoce, igualmente, que hay una escala de perfección en el amor y que no todas las expresiones son igualmente transparentes en la Fuente originaria. No formula la noción de analogía del amor (analogía amoris), como otros pensadores desarrollarán en el siglo xx, porque esta categoría metafísica y teológica es desconocida en su círculo intelectual, pero entiende que el amor se dice de muchas maneras.

El pensador danés escribe: «Toda vida, e igualmente la del amor, está escondida como tal, pero se revela en otra cosa. La vida del pensamiento está escondida, la expresión hablada es lo que la revela» ${ }^{8}$. En efecto, el amor se expresa de diferentes formas en el marco de la exterioridad, pero tiene una vida secreta, una lógica interna, una dinámica intrínseca. Como hace ver Michael Strawser en «The Ethics of Love in Spinoza and Kierkegaard and the Theological Suspensión of the Theological», el origen del amor en el pensamiento de Kierkegaard es misterioso, no se puede captar con la razón filosófica9

8 Las obras del amor, p. 25. Texto original: «Ethvert Liv, saaledes ogsaa Kjerlighedens, er skjult som saadant, men aabenbart i et Andet. Plantens Liv er skjult, Frugten er Aabenbaringen; Tankens Liv er skjult, Talens Yttring det Aabenbarende» (KG 14).

Escribe Michel Strawser: «This emphasis is clearly found in Kierkegaard, a renowned deconstructor of philosophical theory, who focuses on the practical works of love and does not wish to speak of love itself, for it is essentially indescriptibable and unspeakable. There can be for Kierkegaard no theory of love, as has been noted, its origins are essentially mysterious», en Philosophy Today 51 (2007) 443. 
La vida del amor (Kjerligheds Liv) está velada, como la del pensamiento (Tanks Liv), pero se expresa en las obras (Gjerninger). Kierkegaard utiliza el símil de la planta. La vida de la planta está escondida, mientras que el fruto es su revelación. La planta manifiesta unos colores, unos olores, una textura, una forma y un volumen, pero lo que la ha hecho ser, crecer y llegar a ser lo que es, la sabia que corre por sus entrañas, es invisible al ojo desnudo, a pesar de ello, si esta sustancia se evapora, la planta muere.

El pensamiento también está oculto en la persona, no se ve reflejado en su rostro, pero se revela en las palabras. Sin embargo, las palabras no pueden contener la potencia del pensamiento. Dios, en la concepción kierkegaardiana, es misterio, es lo Totalmente Otro, la Absoluta Diferencia (det absolute Forsjkel), pero se revela a través de sus obras, el mundo y, particularmente, mediante su Palabra (Ordet).

A lo largo de la obra, Kierkegaard define el amor de diferentes formas. Lo define como un sentimiento (Følelse), como un estado de ánimo (Stemming), como una vida (Liv), como una pasión (Lidenskab), también como una privación o constante anhelo. Recoge la herencia platónica y socrática, que parte del amor entendido como eros, pero incorpora elementos cristianos, especialmente juánicos y paulinos, cuando concibe el amor como ágape, como la práctica de la donación. Dentro de este conjunto de elementos, sobresale, especialmente, una visión del amor; la del amor como deber, como mandamiento. Esa idea que nutre gran parte de Las obras del amor, se fundamenta en Mateo 22, 39.

No cabe duda de que esta visión del amor como anhelo constante, dinamismo de trascendencia, tiene inequívocas raíces románticas. El amor es anhelo de plenitud, y, en tanto que anhelo, que nunca alcanza su meta, es sufrimiento, dolor, que da sentido a la existencia pero a la vez, trastorna anímicamente a la persona.

Articula, al fin y al cabo, un discurso apofático sobre el amor. En el prólogo (Forord) de la segunda parte, alerta que el amor es esencialmente inagotable (vasentligen uudtømmeligt), esencialmente indescriptible (vcesentligen ubeskriveligt $)^{10}$, pero también construye, dialécticamente un discurso meditativo cuya finalidad es descubrir las obras del amor (Kjerlighed Gjerninger), es decir, sus manifestaciones externas ${ }^{11}$.

Las afirmaciones formuladas se neutralizan con las negaciones que siguen. Al afirmar que es un sentimiento, inmediatamente después afirma que es más que un sentimiento. Al describirlo como una pasión, alerta, sin embargo, que es más que una pasión humana. A través de este juego dialéctico entre afirmación (primer momento) y negación (segundo momento) construye un discurso sobre el amor que, sin fijar la idea, permite al lector adentrarse en el misterio de lo que se evoca y le hace ver que el amor va siempre más allá de la idea (au délà de l’idée) dicho con Emmanuel Levinas. «En lo más íntimo de un ser humano - afirma Kierkegaard- existe un lugar; de este lugar brota la

10 La cursiva es de Kierkegaard. Las obras del amor, p. 251. KG, 5.

11 Nishitani, K., (Noto 1900-Kioto 1990), último gran representante de la denominada Escuela de Kioto, sintetiza el contenido de Kjerlighed Gjerninger així: «Kierkegaard señala, en sus Obras del amor, que el mandato implica penetrar en el secreto más hondo del amor del hombre por sí mismo y contiene la inmediatez de la severa negación característica de lo eterno. Requiere la negación absoluta del amor de sí (y en consecuencia, del yo). Esto quiere decir hacer del yo una nada y hacer de los demás un sujeto opuesto al yo - es decir, hacer del yo un siervo y de los demás su señor - viene a significar que el otro sea amado tal como es y allí donde se manifiesta como es en su propio fundamento. Significa amar al otro justo como es: amarlo como pecador si es un pecador, como enemigo si es un enemigo. Es el amor indiferenciador que hace que brille el sol tanto sobre buenos como sobre malos. Kierkegaard dice que en su amor al prójimo, el hombre se asemeja a Dios y se hace uno con él» (La religión y la nada, Siruela, Madrid, 1999, p. 346). 
vida del amor, porque 'del corazón brota la vida'. Pero este lugar no lo puedes ver; por mucho que te adentres en él, el origen se remonta en la lejanía y la ocultación, aunque te hubieras adentrado hasta lo máximo posible, el origen se encontraría aún como un poco más adentro, como pasa con el origen de la fuente, que precisamente cuanto más te acercas, más lejos estás de ella» ${ }^{12}$.

Utilizando una imagen de resonancias románticas, Kierkegaard compara la fuente del amor con la fuente de un lago. Nadie la puede ver, y a pesar de ello el lago existe, y subsiste gracias a la secreta fuente que lo nutre. La fuente mana agua. Lo mismo ocurre con el amor. Esa fuente, en el pensamiento del escritor danés, evoca la imagen de Dios.

Las obras del amor se fundamentan en la vida secreta del amor que se desarrolla en la intimidad del ser personal. No es posible llegar a este origen, porque siempre está más allá, como sucede con la línea del horizonte en el mar. El acercamiento a la fuente es asintótico; se mantiene una alteridad radical que el ser humano es incapaz de alcanzar y de disolver.

En la medida en que el ser humano expresa este amor que emana de su interior, que lo hace manifiesto en su vida exterior, a través de las palabras, de los gestos y de las acciones, se hace semejante a Dios, porque Él es el Amante y el Amado absoluto en cuyo seno se engendra el amor. Fuera de Dios es imposible amar, de forma que el ser humano se comprende en este dinamismo circular que lo conduce a su origen. Este origen es divino, y por tanto, difusivo en sí mismo, pura manifestación creadora que irradia gratuitamente ad extra.

Escribe J. Binetti: «Kierkegaard atribuye al amor un dinamismo eterno, definido como 'una duplicación en sí mismo', vale decir, como un devenir reflexivo que, sin abandonar la igualdad, afirma lo otro en su absoluta unidad. La reflexión del amor obedece a su sobreabundancia esencial, a esa riqueza difusiva, por la cual él se autodetermina en una nueva creación. En virtud de esta duplicación, lo que el amor es en sí mismo, el fundamento de todo, se convierte en su propia obra» ${ }^{13}$.

Este amor, tal como escribe Álvaro M. L. Valls, es independiente de las circunstancias del mundo, de las metamorfosis exteriores, porque no tiene una génesis humana. La transciende, tanto por lo que respecta a su origen como por lo que respecta a su expresión ${ }^{14}$. Sin embargo, Kierkegaard reconoce la ambigüedad de las obras y afirma que los frutos no muestran, necesariamente, la pureza del amor. Puede ser que las obras parezcan obras del amor pero que, en el fondo, sean expresiones del egoísmo humano. La intencionalidad no queda siempre reflejada en la obra y solamente Dios conoce la verdadera intencionalidad de quien ha hecho aquella obra.

El pensador de Copenhague distingue distintas formas de amor en una escala de perfección. El ser humano está llamado a amar, hecho para amar. Partiendo del subsuelo

12 Las obras del amor, p. 25. Texto original: «Der er et Sted i et Menneskes Inderste; fra dette Sted udgaaer Kjerlighedens Liv, thi 'fra Hjertet udgaaer Livet'. Men see dette Sted kan Du ikke; hvor langt Du end trænger ind, Oprindelsen unddrager sig i Fjernhed og Skjulthed; selv naar Du er trængt længst ind, Oprindelsen er endnu bestandig som et Stykke længere inde, ligesom Kildens Udspring, der just, naar du er det nærmest, er længere borte» (KG 14).

13 BinetTi, M. J., «El estadio religioso de Kierkegaard en las categorías lógicas de Hegel: identidad y diferencia», en Estudios Filosóficos 166 (2008) 418.

14 Escribe VALLS, A. L. M.: «Este amor não apenas reage às relações intramundanas, mas antes obedece a um sentido que de certo modo está fora do mundo. Este amor independe das circunstãncias do mundo e das mudanças da pessoa amada, pois se funda num 'dever' eterno. É incompreensível para o mundo, e ocasião de escândalo, é 'prudente'. É risco que o crente assume», en Sobre as críticas ao cristianismo e à cristiandade em Nietzsche e em Kierkegaard, 34/110 (2007) 404. 
de la antropología agustiniana, Kierkegaard entiende que el ser humano está orientado, teleológicamente, hacia el amor. Está hecho para amar y todo en él llama al amor. Se inscribe, pues, en la misma tradición filosófica, según la cual el ser humano es ens capax amoris, tesis que desarrollarán, en el siglo xx, pensadores como Max Scheler, Gabriel Marcel, Maurice Nédoncelle o Paul-Ludwig Landsberg entre otros.

Desde el amor primario y egocéntrico que encarna la figura mítica del don Giovanni, expresado en el personaje central de El diario de un seductor (Forførens Dagbog) $(1843)^{15}$, hasta el amor de desposesión y de abandono de Abraham por su hijo Isaac, capaz, como Kierkegaard subraya en Temor y Temblor (Frygt og Baven), de una renuncia infinita, por fidelidad al mandato de Dios, el amor recorre distintos grados de perfección en un movimiento progresivamente ascendente.

La necesidad de amor es intrínseca al ser humano, se encuentra profundamente enraizada en él, de tal manera que es un ente indigente de amor. El anhelo de ser reconocido y conocido es un vector fundamental de la existencia humana. La felicidad radica, como veremos, en amar y ser amado. En este punto, Kierkegaard se opone al intelectualismo racionalista de los idealistas alemanes y subraya que el órgano central de la persona no es la cabeza, sino el corazón.

Según el pensador danés, este anhelo está profundamente insertado en la condición humana. A su modo de entender, desde la creación no ha habido ningún cambio en este campo, ni se ha hecho ningún descubrimiento nuevo; únicamente se ha confirmado la misma observación una y otra vez. Sin embargo, los seres humanos buscan subterfugios, formas de sustraerse al amor. Al hacerlo, se engañan a sí mismos y se destruyen. Estamos hechos para amar y ser amados, tanto en un sentido activo como pasivo.

El amor es la teleología inherente a la condición humana, es su tendencia más íntima. Es lo que hace que la vida merezca ser vivida, lo que da sentido a su existencia. La entiende como aquella potencia interior que conduce al ser humano fuera de sí mismo para entregarse al objeto de amor, como lo que lo pone en movimiento, su fuerza motriz o causa eficiente. En tanto que ser capax amoris solamente alcanza su plenitud si se siente amado y es capaz de amar en plenitud.

El ejercicio del amor exige un largo aprendizaje, un trabajo de purificación interior y exterior que transita desde las formas primarias y aún instintivas del amor, centradas en la preponderancia del ego, hasta el amor sublime que se ha liberado del ego y alcanza las máximas cotas de excelencia y de plenitud, que se da gratuitamente y que, incluso, es capaz de dar la vida.

Este largo periplo del amor se puede describir como el paso (Overgang) del amor autocéntrico, en el que el centro es el autos, hacia el amor heterocéntrico, en el que el centro pasa a ser el heteros, pero esta transición solo es posible si se reconoce dentro del autos (Selvet), al Otro (heteros) infinito que actúa y obra en el yo (sig selvet), liberándolo de la tendencia a encerrarse dentro de sí mismo.

El amor pleno exige la abnegación de sí mismo (sig selvet), pero esta negación de uno mismo no significa la desintegración de la propia identidad, sino la capacidad de comprender el yo como don que se da gratuitamente a los demás. Kierkegaard defiende la singularidad radical del ser humano frente al mundo y frente a Dios. Repite que el ser humano es un individuo frente a Dios (en Enkelte for Gud). Amar (Elske) no significa renunciar a la individualidad (Enkeltheden) sino liberar esta individualidad del ego para poderla dar generosamente a los demás.

15 Forma parte de la obra Enten Eller. Første Deel ( $O$ esto o aquello. Primera parte), publicada bajo el pseudónimo Victor Eremita. Fue publicada en Copenhague el día 20 de febrero de 1843. 
El amor puro (der rene Kjerlighed) o amor eterno (den evige Kjerlighed) nace del espíritu $(\text { Aand })^{16}$. Tal y como expresa en El concepto de la angustia ((Begrebet Angest) $(1844)^{17}$, parte de una concepción tridimensional del ser humano: cuerpo, alma y espíritu. El ser humano es espíritu desde el mismo instante de nacer, aunque en aquel momento no es consciente de serlo, pero llegará a serlo cuando se distancie del mundo.

El espíritu (Aand) es lo que de divino hay en el ser humano, la semilla de eternidad encerrada en su ser. El espíritu es invisible y su lenguaje es un secreto. Dios deposita en cada ser humano el espíritu y, de este espíritu, nace el amor, porque Dios mismo es amor (Gud er Kjerlighed).

A grandes rasgos, Søren Kierkegaard distingue a lo largo de su filosofía del amor dos formas fundamentales: el amor inmaduro o inmediato (den umiddelbare Kjerlighed) y el amor eterno (den evige Kjerlighed). El amor inmediato tiene como objeto lo bello. Su destinatario es el objeto inmediato y directo, es una elección de la inclinación y de la pasión. El amor eterno tiene como finalidad el prójimo y el prójimo es lo no amable, no es algo ofrecido a la inclinación y a la pasión.

$\mathrm{El}$ amor eterno es un mandato, pero un mandato que nunca envejece, que siempre se renueva a sí mismo. Dicho de una forma clara: se trata de amar al otro, pero amándolo cada día como si fuera la primera vez. El amor al prójimo no se basa en el recuerdo ni tampoco en la esperanza futura. Se proyecta en el presente y no vive del pasado, ni del futuro. En él tiene lugar el movimiento de la repetición (Gjentagelsen).

A su modo de ver, el propósito fundamental del cristianismo es extirpar del corazón humano la semilla del egoísmo, abrirlo al amor más grande, reconciliar al ser humano con su origen, con su Fuente creadora, de la que proviene y hacia la cual está, metafísicamente, orientado. La felicidad consiste en la reconciliación, en la trasparencia entre su voluntad y la Voluntad de Aquel que habita en la interioridad. Mientras esta conformidad no tenga lugar, el ser humano vive en tensión interior con su Fuente creadora, con lo que es.

El pensador danés escribe: «El amor inmaduro y engañoso se conoce porque su único fruto son las palabras y las frases hechas ${ }^{18}$. Esta forma de amor deficiente se expresa únicamente en las palabras, pero no en las obras. El amor verdadero, en cambio, es discreto en las palabras, pero se traduce en obras que tienen como finalidad el cuidado del otro, la promoción de su ser, y el desarrollo de todas sus facultades. La cualidad de la vida del amor se expresa en las obras que de él emergen.

En el amor inmaduro falta el descentramiento, porque aún gravita alrededor del ego; le falta la potencia de la desposesión, porque aún tiende a poseer todo lo que gira a su alrededor, y a convertir en objeto toda realidad exterior a sí mismo. Es pasión, apego, anhelo de una presencia, deseo de un ser. No contempla el sacrificio, la abnegación, el trabajo de desapego que es la condición de posibilidad de la libertad del otro. Este amor carece de un profundo ejercicio de liberación interior de los prejuicios y de las

16 Escribe STRawser, M.: «Kjerlighed is active rather than passive, and inclusive rather exclusive. This love is not an unfree reaction caused by external forces; it is a free action produced from within the inner self (the true self), an action that we may consider to be as difficult as it is rare or more difficult than to capture a city», en "The Ethics of Love in Spinoza and Kierkegaard and the Teleological Suspension of the Theological», en Philosophy Today 51/4 (2007) 442.

17 Fue publicada el 17 de junio de 1844 con el seudónimo de Vigilius Haufniensis.

18 Las obras del amor, p. 29. Texto original: «Den umodne og den bedragerske Kjerlighed er kjendelig paa, at Ord og Talemaader er dens eneste Frugt» (KG, 13). 
diferencias, de la servidumbre de las simpatías y antipatías que lo hacen esclavo del ojo sensible (det sandselige Øie) ${ }^{19}$.

El amor inmediato se nutre del plan exterior de la persona, nace de las apetencias, o de lo que kantianamente se podría denominar les inclinaciones (die Neigungen). Es un amor movido por el interés personal, por el propio beneficio y bienestar. En este sentido, es una traición a la Fuente secreta del amor, que mueve a todo ser humano hacia la excentricidad, y hacia la donación incondicional. Tiene la misma raíz, está nutrido por la misma Fuente, pero no es capaz todavía de elevarse al nivel de sus posibilidades.

Es, pues, un amor relativo, inconstante, inconsistente y esclavo de las percepciones, del gusto y del disgusto, servil y también expuesto a cualquier forma de mutación y transformación.

La vida del amor (Kjerligheds Liv) es conocida por sus frutos, pero trasciende a los frutos. Es más que sus expresiones. Las manifestaciones no agotan la riqueza del amor, su potencialidad, de la misma forma que la obra no agota la riqueza del artista, aunque a través de ella, podemos vislumbrar la potencia de su genio creativo. La encarnación del amor inmaduro es el mito de don Juan, un amor suscitado por la fascinación formal, pero incapaz de permanecer fiel a sí mismo a lo largo del tiempo ${ }^{20}$. Søren Kierkegaard expone este tipo de amor a través de esta figura literaria que encarna el estadio estético de la existencia y que pone de manifiesto a través del conocido Diario de un seductor.

El amor inmaduro se basa en la práctica de la comparación. "Comparar —escribe Kierkegaard- es autoinmolarse ${ }^{21}$. En este ejercicio se pone de manifiesto que el amor aún no ha alcanzado su plenitud, porque todavía está pendiente de lo que recibe, desconoce la categoría de la gratuidad y compara lo recibido con lo dado. Cuando el amor es netamente gratuito, no mira de reojo lo que el otro recibe, lo que el otro da; no se pregunta quién ha amado más, porque, sencillamente, no compara.

La comparación es la raíz de la violencia y del malestar. Cuando uno constata que no es amado como le gustaría, que no recibe como ha dado, experimenta malestar; pero este malestar es fruto de la comparación, y la comparación es una expresión del amor inmaduro. Quien vive conforme al amor eterno se congratula solamente con dar, con actuar sin esperar nada ni comparar lo que recibe con lo que da. Da siempre y en todo lugar sin calcular el retorno.

La comparación es, al fin y al cabo, una forma de destrucción de uno mismo y del amor. En lugar de agradecer el don recibido y de desarrollarlo a su máximo nivel, el amante se consume al comparar sus dones con los dones de los demás. Experimenta, por consiguiente, el resentimiento por no tenerlo y no es capaz de reconocer los propios dones que, generosamente, le han sido concedidos.

19 A este amor se lo denomina con la palabra danesa Elskov. Dice STRAWSER, M.: «Elskov is used to refer what is also called 'self-love' (although 'self' is ambiguously used by Kierkegaard as we shall soon see, and thus I would distinguish between 'self' and 'ego' and then can this 'ego-love'), 'spontaneous love', 'preferential love', 'erotic o romantic love', and 'friendhip', en "The Ethics of Love in Spinoza and Kierkegaard and the Teleological suspension of the Theological», en Philosophy Today 51/4 (2007) 42.

20 Escribe Valls, A. L. M.: «Amor ao próximo é diferente do desejar a próxima, que caracteriza o insaciável Don Giovanni, em seu amor de perdição, que, instantâneo e sem história, jamais se concentra e não escapa às forças do tempo. $\mathrm{O}$ amor ao próximo é um amor prático, não necessariamente 'patologico’ (Kant), pois não se baseia em sentimentos, instintos, preferências ou inclinações, mas no dever, no mandamiento", en VALls, A. L. M., Sobre as críticas ao cristianismo e à cristandade em Nietzsche e em Kierkegaard, 34/110 (2007) 406.

${ }_{21}^{21}$ Las obras del amor, p. 57. Texto original: «Sammenligningen er Selvantændelsen» (KG, 40). 
Søren Kierkegaard es especialmente plástico en sus descripciones de la comparación. La define como un gusano escondido que no muere hasta que no ha matado la vida del amor (Kjerligheds Liv), o también como una erupción repugnante que penetra en su ser y corrompe la médula. La enfermedad de los celos es fruto de la comparación y la comparación es la expresión diáfana del amor inmaduro ${ }^{22}$.

El amor inmaduro es, al fin y al cabo, un amor desesperado, que experimenta la angustia del tiempo, que carece de la perspectiva de la eternidad. Estamos hechos para amar a fondo. Queremos ser amados de una forma incondicional. El amor inconsistente genera todo tipo de angustias y sufrimientos, porque nadie sabe durante cuánto tiempo será amado, ni tampoco es capaz de garantizar un amor fiel. Esta inconsistencia del vínculo causa desesperación, porque anhelamos la eternidad; pero también huimos del deber de amar eternamente. Escribe Kierkegaard: «No es la desgracia la que hace desesperar a un ser humano, sino que le falte lo eterno. Desesperación significa que falta lo eterno" ${ }^{23}$.

La desesperación es que te falte lo eterno (Fortvivlelse er at mangle det Evige). Kierkegaard dedica una obra a explorar la noción de desesperación. Nos referimos a $L a$ enfermedad mortal (Sygdommen til Døden), que publica en el mes de julio de 1849, bajo el seudónimo de Johannes Anticlimacus, dos años después de la edición de Las obras del amor.

Allí concibe la desesperación como una enfermedad espiritual, como un desequilibrio entre las potencialidades del yo, entre finitud e infinitud, entre temporalidad y eternidad, entre necesidad y libertad. La desesperación a que se refiere en Las obras del amor es a la falta de eternidad, que adviene cuando el ser humano se comprende a sí mismo como un ser finito y temporal, abocado a la nada.

El amor inmediato es desesperación (Den umiddelbare Kjerlighed er saaledes Fortvivlelse). Siempre está expuesto a la angustia porque está sometido al cambio y esta fragilidad constitutiva es generadora de todo tipo de angustias. La desesperación, tal y como la describe en esta obra firmada, consiste en el hecho de relacionarse, con pasión infinita, con un ser humano concreto, histórico y relativo.

La pasión infinita solo puede tener como destinatario a quien es infinito y merece ser amado de esta forma; a saber, Dios. El amor inmediato no se asienta sobre la fidelidad eterna, no descansa sobre la convicción de que pase lo que pase, suceda lo que suceda, este amor permanece inalterable a sí mismo. El amor inmediato está sometido al cambio y se puede transformar en lo contrario de lo que es: en odio.

En este análisis de las tipologías del amor, Kierkegaard explora la pasión amorosa bajo la forma del enamoramiento que no ubica en el amor inmediato, en la medida en que es fruto de una potencia infinita orientada hacia un ser finito, pero tampoco la coloca como una forma elevada de amor.

A su modo ver, la pasión amorosa no es el amor eterno (evige Kjerlighed), aunque haya algo de eterno en él. Es el maravilloso vértigo de la infinitud, el temor frente a lo enigmático. Consiste en amar a un ser finito de una forma infinita, a convertirlo en Dios. Esta forma de amor solamente puede conducir a la desesperación, porque el sujeto amado no puede vencer, por sí mismo, la finitud, y el escenario final es su muerte. Solo

${ }^{22}$ El término utilizado por Kierkegaard es Iversyge que en danés significa literalmente: enfermedad del afán.

${ }^{23}$ Ibídem, p. 63. Texto original: «Det, der nemlig gjør et Menneske fortvivlet, er ikke Ulykken, men er, at han mangle det Evige» (KG, 46). 
tiene sentido amar al Infinito de una forma infinita, pero amar al finito de una forma infinita es la raíz de la desesperación.

El amor pleno no es esclavo de los sentidos, ni de las percepciones. No contempla al otro con los ojos físicos, sino con el ojo espiritual. Kierkegaard reconoce en el ser humano un oído espiritual, que es el fundamento y la raíz de la oración, la condición de posibilidad de la escucha de la Palabra de Dios y por tanto, de comunicación entre el ser humano y lo Eterno. Asimismo, también reconoce un ojo espiritual en la persona, que la hace capaz de contemplar a los demás con profundidad, trascendiendo las apariencias. Desde la percepción del ojo espiritual, todo ser humano es igualmente digno de respeto, indistintamente de sus características externas, porque desde este órgano, se ve lo esencial que une a todos los seres humanos.

Al mismo tiempo reconoce que el ser humano es capaz, también, de contemplar el mundo con el ojo espiritual y este ojo permite contemplar al otro sin hacer diferencias ni discriminaciones; permite verlo y concebirlo como un ser humano, como un hermano en la existencia, como un reflejo de la grandeza infinita de Dios. El pensador danés escribe: «Al prójimo solo se le ve con los ojos cerrados o pasando por alto las diversidades. El ojo sensible siempre ve las diversidades y siempre mira las diversidades» ${ }^{24}$.

Más allá del ojo sensible, Kierkegaard reconoce en el ser humano el ojo espiritual, que lo capacita para captar lo que es invisible a la mirada externa y que trasciende las apariencias. El pensador danés escribe: «Cierra los ojos y recuerda el mandamiento de que $t u ́$ tienes que amar» ${ }^{25}$. El imperativo es claro: tienes que amar (Du skal elsker), pero el objeto directo también es nítido: cualquier ser humano, este o aquel, próximo o lejano; pero, esto sí, un ser humano concreto e histórico. Kierkegaard entiende que el amor al prójimo se concreta, siempre, en este individuo singular (dette Enkelte).

Una de las formas evasivas del amor tiene lugar cuando se proyecta hacia lo impersonal y abstracto, cuando pierde la referencia histórica, encarnada. El amor impersonal, orientado hacia lo invisible, o bien hacia la humanidad in abstracto, es una forma de autoexcusarse, de desenvolverse de la historia.

Siguiendo las intuiciones de la Primera carta de san Juan, Kierkegaard entiende que, solo quien ama a aquel ser visible que se le aproxima, puede amar al Ser invisible que nunca ha visto. Existe la tendencia a amar a un ser imaginario, no a aquel ser concreto, con sus debilidades y fortalezas, necesidades y posibilidades, sino a un ser ideal, que es la transformación de mi semejante en lo que me gustaría que fuera. El subterfugio más peligroso respecto al hecho de amar — escribe Kierkegaard - es pretender amar exclusivamente a lo que es invisible, a lo que nadie ha visto nunca.

Según Kierkegaard, el amor es la raíz de la liberación, la fuerza que aniquila al ego y libera al ser humano de la servidumbre de sí mismo, y le predispone a amar de una forma universal e incondicional a todos los seres humanos.

La libertad (Friheden), tal y como la percibe Kierkegaard, no es el mero ejercicio de elegir entre dos o más alternativas, al modo del libre albedrío (libedrum arbitrium); es un proceso de liberación del ego cuyo objeto final es la plenitud del ser humano y la plena expresión de aquella Fuente eterna de amor que lo nutre.

24 Ibídem, p. 95. La cursiva es de Kierkegaard. Texto original: «Naesten seer man kun med lukket Øiet eller ved at see fra Forskjelligherdene. Det sandselige Øie seer altid Forskjellighederne og seer til Forskjelligherdene».

${ }_{25}$ Ibídem, p. 94. La cursiva és de Kierkegaard. Texto original: «Luk Øiet,og husk paa Budet, at Du skal Elske, saa Elsker Du». 
Solamente el amor que fluye de la Fuente eterna que está en el interior del ser humano es verdaderamente libre e independiente de las filias y de las fobias, de las preferencias y de los prejuicios.

Este amor sin interés, que se expresa como un deber (Pligt) pero que no emerge de la razón pura práctica, sino que la trasciende, es el único que de verdad puede hacer libre al ser humano, porque lo libera de toda clase de prejuicios y de apetencias personales y le ensancha la mirada hasta tal extremo que el otro se convierte en el prójimo.

De esta forma aprende a amar a todos los seres humanos, a los próximos y a los lejanos, a los pobres y a los ricos, a los amigos y a los enemigos, todos de una forma idéntica. El deber de amar al prójimo es la verdadera clave de la libertad. Es un amor que exige abnegación y sufrimiento por el prójimo.

A diferencia de los maestros de la sospecha, Kierkegaard no entiende contradictoria la afirmación de la existencia de Dios y, a la vez, la afirmación de la libertad humana. No entiende que Dios sea un obstáculo o una interferencia en el proceso de liberación del ser humano, sino todo lo contrario: concibe que Dios es la Fuerza de liberación interior, aquella Energía que lo llama a ser plenamente libre y a liberarse del amor inmediato. No en vano entiende que el cristianismo es, con plena propiedad, la religión de la libertad (Frihedens Religion).

Dios es la condición de posibilidad de la libertad del ser humano, entendiendo esta libertad como la plena liberación del ego, la total realización de las aspiraciones del ser humano ${ }^{26}$. Lo Eterno confiere universalidad al amor, porque no está ligado a nada ni a nadie y libera al ser humano de su egoísmo y pasión, de sus mezquindades y prejuicios. El amor eterno es, a su modo de ver, el único camino hacia la liberad. María J. Binetti escribe: «Dios es Amor perfecto, su donación no es pérdida de sí y su sufrimiento no lo cambia. Además, precisamente porque el hombre proviene de este amor, hay en él un principio de vida inmutable, que ignora toda lucha dialéctica y se retorna en la entrega generosa. Cuando la libertad ha devenido sí misma, ella es amor que gratis se recibe y asimismo se da. Más aún, en el amor, la necesidad libre no es carencia sino plenitud expansiva: bien difusivo de sí» ${ }^{27}$.

\section{Culalidades DEL AMOR}

Toda la constelación de cualidades del amor que Kierkegaard desarrolla en la obra que comentamos se inspira en la descripción del amor que desarrolla san Pablo en la Carta a los Corintios (capítulo 13). "La equidad - afirma Kierkegaard- consiste básicamente en que no se discrimine, y la equidad eterna consiste en que no se discrimine incondicionalmente lo más mínimo; en que ilimitadamente no se discrimine lo más mínimo; mientras que la predilección consiste en discriminar, y la predilección apasionada a discriminar ilimitadamente ${ }^{28}$.

26 Escribe Pegueroles, J.: «Dios ayuda la libertad del hombre a hacer lo que sólo la libertad puede hacer. Y el hombre le da gracias a Dios, como si lo que la libertad ha hecho lo hubiera hecho Dios. Porque sólo Dios podría hacerlo y a la vez sólo la libertad podía hacerlo», en "Amor, sufrimiento y alegría. Dios en el Diario de Kierkegaard», en Espíritu 129 (2004) 29.

27 Binetti, M. J., "Algunos puntos clave de la libertad kierkegaardiana», en Anuario Filosófico XXXIX/3 (2006) 669.

${ }_{28}$ Ibídem, p. 82. Texto original: «Ligelighed er jo just, ikke at gjøre Forskjel, og evig Ligelighed er, ubetinget ikke at gjøre den mindste Forskjel, grændseløst ikke at gjøre den mindste Forskjel; Forkjerlighed derimod, at gjøre Forskjel, lidenskabelig Forskjerlighed, grændseløst at gjøre Forskjel» $(\mathrm{KG}, 65)$. 
El amor puro, tal y como lo concibe Kierkegaard, no discrimina, trata a todos de una forma igual, pero sin sucumbir a la homogenización. La equidad (ligelighed) es la consecuencia de un amor que no marca diferencias, que no cae en el amor de predilección.

Quien ama movido por esta Fuerza interior atiende a todo el mundo, pero también atiende a cada uno según sus necesidades y posibilidades. No existe una razón apriorística que justifique la discriminación, más bien al contrario. Nadie es extraño, nadie es extranjero, porque todos son seres humanos, capaces de amar y de ser amados.

Este amor introduce una plena equidad y conmueve cualquier barrera u ostracismo; pero este amor equitativo tampoco sucumbe a un proceso de homogeneización, sino que se expresa en cada persona según sus propias capacidades y necesidades.

Por causa del amor que fluye desde el fondo más íntimo de la persona, el otro deja de ser otro, pero no para convertirse en lo mismo, sino para ser el prójimo. El amor no tiene como finalidad convertir al otro en una prolongación de sí mismo, sino que se pone a su servicio para que llegue a ser lo que, interiormente, está llamado a ser. El amor no limita ni mutila el proyecto de cada ser, sino que, en la medida en que quiere el bien ajeno, se somete a él.

El prójimo es el primer tú (Naesten er det forste $\mathrm{Du}$ ). Al concebir al otro como prójimo, deja de ser un cuerpo inerte, un ser anónimo, para convertirse en un tú. En este amor desaparece la diferencia entre amar al amigo y al enemigo, porque quien ama al otro como al prójimo no le ama porque le sea próximo o lejano, receptivo o antipático; tampoco lo ama esperando gratitud, reconocimiento o alguna forma de reciprocidad. Obedece a un imperativo que resuena en su conciencia, una voz que se le impone como un deber universal: tú tienes que amar a tu prójimo (Du skal elsker til Naesten).

Cuando el filósofo danés se refiere al prójimo, no lo concibe como un ideal ni como una entelequia, tampoco como una abstracción. El prójimo (Naesten) no es la humani$\operatorname{dad}^{29}$. Es un ser humano de "carne y hueso» como diría don Miguel de Unamuno; un ser humano único, diferente, singular, una individualidad (Enkeltheden) en la historia. El amor exige una trascendencia del ego, pero no una disolución del individuo (Enkelte) porque, sin individuo, no hay amor.

El filósofo danés expresa con mucha claridad esta singularidad del ser humano, su carácter irreemplazable. La ventaja del ser humano sobre el animal no es pertenecer al género humano, sino algo que solemos olvidar, que cada individualidad constituye lo esencialmente diferente dentro del género humano. Esta unicidad irreductible de cada ser humano, que lo hace ser particular y singular frente a los demás y a Dios, es imborrable. Es su máxima riqueza, la raíz de su dignidad, lo que hace que su vida sea inconmensurable.

El amor se concreta siempre en un acto concreto y personalizado, a diferencia del altruismo o de la filantropía que se proyecta hacia la humanidad y que Kierkegaard critica abundantemente, porque cae en lo etéreo e impersonal y rehúsa la inefabilidad de la individualidad.

Amar al prójimo es ensanchar indefinidamente los límites del propio amor egoísta y trascenderlo a través de un amor que no tiene límites ni fronteras. El ser humano no es capaz de llevar a cabo este movimiento por sí mismo, pero, en el fondo, de su ser, existe una semilla de eternidad, el epicentro de esta transformación. Esta Fuente le llama a

29 Dice Strawser, M.: «The neighbor is the 'nearest', not in the sense of 'preferential love', but in the sense of essential love in which case I understand myself not as he, man, teacher, husband, father, o coach, but rather as 'one who is equal' or similar to all others. Conceptually, Kierkegaard tells us, the neighbor is 'a redoubling of your own self', en «The Ethics of Love in Spinoza and Kierkegaard and the Teleological Suspension of the Theological», en Philosophy Today 51/4 (2007) 442. 
trascenderse, a salir fuera de sí mismo para darse. En este sentido, el amor es, como el espíritu, motor invisible, un dinamismo que empuja a salir, a practicar la excentricidad, a abandonar el propio centro para vencer el narcisismo y orientarse hacia el otro.

Álvaro L. M. Valls considera que, en esta concepción del amor, se puede vislumbrar la huella del pensamiento de Immanuel Kant, dado que Kierkegaard califica el amor como un deber (Pligt) que brota del estrato más profundo de la conciencia humana.

Es cierto que el filósofo danés concibe el amor pleno como un deber que trasciende la ley, pero este deber no emerge de la razón pura práctica (die reine praktische Vernunft) al modo de Kant, ni es la expresión de un imperativo categórico que resuena dentro de la conciencia de una forma autónoma, como una ley universal, formal y santa (ein heiliges Gesetz). No es, tampoco, un sentimiento que fluye del corazón a la manera como es concebido por los emotivistas morales.

Este deber es escuchado por el ser humano en el sagrario de su conciencia, pero no proviene de él, sino que proviene del Otro que hay en él. Tiene, pues, una raíz heterónoma, aunque solamente puede auscultarse en el interior del autos (Selvet). El Otro resuena dentro de sí mismo, pero no puede identificarse con el sí mismo. Este Otro, sin embargo, no es propiamente una voz extrínseca, ni un ser que susurra suavemente.

Es un amor incondicional, que trasciende a los instintos o las inclinaciones (die Neigungen) por utilizar la misma terminología kantiana ${ }^{30}$, pero al mismo tiempo también las fronteras de la razón (die Grenze der Vernunft), no solo por lo que respecta a su génesis, sino también por lo que respecta a su orientación final.

En este sentido, aunque la formulación del amor como deber tiene, irremisiblemente, resonancias kantianas, no es kantiana la génesis del amor en Kierkegaard, sino agustiniana, en la medida en que entiende a Dios como Aquel que es más íntimo a mí mismo que, desde el fondo de la conciencia, me llama, me convoca a salir de mí mismo para dar lo que soy a los demás.

El amor no hace distinciones, ni separa, ni discrimina, ni jerarquiza, porque brota de las profundidades y reconoce la infinita dignidad de todo ser humano y no depende de sus características externas. Se fija en el ser humano desnudo. No se basa en predilecciones ni se mueve por las afinidades o las antipatías. Brota del interior, y, en este sentido iguala a todos los seres, aunque, también, trata a cada uno de ellos según sus necesidades y posibilidades. No es esta una discriminación apriorística, pero sí una atención singularizada buscando el mejor bien de cada destinatario. Desnuda los elementos adyacentes, las particularidades que nos distinguen a los unos de los otros, y con frecuencia, se convierten en verdaderas murallas para relacionarnos. Se centra en lo invisible del otro, en aquella semilla de eternidad que reposa en su ser, el espíritu eterno.

El amor, como la muerte, lo iguala todo. En efecto, la muerte, cuando hace acto de presencia en la vida del ser humano, no distingue entre ricos y pobres, ni discrimina en virtud de otras características. Se impone, de una forma universal, a todos, y, en este sentido, solamente el amor y la muerte hermana, hacen tomar conciencia de nuestra idéntica condición lábil.

Somos seres hechos para amar, y somos seres urgidos de amor, pero, al mismo tiempo, estamos destinados a la muerte. Somos seres mortales, irremisiblemente finitos y caducos. Con todo, el principio eterno que habita en la interioridad humana es

30 Escribe Valls, A. L. M.: «Há muito de kantiano, mas não tudo, na compreensão kierkegaardiana do amor, deste amor que se mostra em obras e age por un dever. Tal amor é em questão de consciência (Gewissen), e se apresenta como incondicional, não se prende aos instintos ou às inclinações naturais», en VAlls, A. L. M. , «Sobre as críticas ao cristianismo e à cristiandade em Nietzsche e em Kierkegaard», en Sintese 34/110 (2007) 405. 
espiritual y, en tanto que espiritual, es ajeno a la muerte. Es aquello de nosotros que sobrevive a la descomposición.

Más allá de las diferencias de calidad y cantidad, la muerte y el amor igualan y neutralizan las diferencias. Søren Kierkegaard escribe: «Cuando al morir caiga el telón sobre el escenario de la realidad [...], todos serán una misma cosa, serán seres humanos, y todos serán lo que esencialmente eran, pero que no veías por causa de la diversidad: verás que son seres humanos» ${ }^{31}$.

El filósofo danés insiste en la idéntica condición de seres humanos, en la raíz común que todos compartimos y que es la fuente de la unidad del género humano y de la fraternidad ética. La muerte deshace las vestimentas, quita las máscaras, desnuda a los personajes sociales. Como el amor, la muerte no tiene en cuenta las particularidades y se expresa a todos por igual.

La determinación fundamental (Grundbestemmelsen) es ser humano. Kierkegaard no distingue, semánticamente, entre ser humano y persona. Utiliza el vocablo Enkeltheden para referirse a la unicidad de cada ser humano, al hecho de ser una individualidad no solamente frente a los hombres, sino frente a Dios. Esta determinación es la clave. Las diferencias raciales, lingüísticas, religiosas, son accidentales. La clave es no olvidar que, antes que nada, un ser humano es un ser humano que merece ser amado incondicionalmente, como un fin en sí mismo.

El amor inmediato solamente capta las diferencias, las particularidades, el rango y el papel que desarrolla una persona en el mundo, pero no es capaz de trascender el velo y captar aquello de esencial y básico, aquello que une a todos los seres humanos, más allá de las cualidades específicas que poseen.

La determinación fundamental es ser persona y el resto adquiere un carácter relativo para quien ama de veras. Aunque, en este texto, Kierkegaard no utiliza la palabra dignidad, ni la palabra valor, parece claro, por lo que se afirma en este texto, que solo la persona tiene dignidad, un valor en sí mismo, en la medida en que solo ella es una singularidad irreductible en la naturaleza. El amor eterno se traduce, pues, en el deber de amar al prójimo, pero el prójimo es cualquier ser humano. Este imperativo se circunscribe en la esfera de los humanos en el caso de Kierkegaard, lo que no significa que no reconozca valor y belleza en el resto de seres de la creación.

Kierkegaard admite que el amor, igual que el ser, se dice de muchas formas. Observa cómo el amor a la esposa es distinto del amor al amigo o bien al prójimo, pero entiende que esta no es una diversidad esencial, sino que todas estas formas distintas brotan de un mismo amor, enraizado en el corazón humano.

El amor eterno iguala, pero el amor de predilección distingue y jerarquiza. Todo ser humano, en tanto que ser familiar, social y político, establece vínculos y estratos de relación de distinta intensidad, calidad y extensión en el tiempo. La predilección es humana, pero este lazo no tiene que ser una excusa para incurrir en formas de discriminación y de desigualdad. «Si quieres ser perfecto en el amor —afirma Kierkegaard—, tienes que esforzarte para llevar a la plenitud este deber de amar amando al ser humano que ves, amarlo tal y como lo ves, con sus imperfecciones y debilidades; amarlo tal y como lo ves, cuando ha cambiado completamente, cuando ya no te ama y quizás te

31 Ibídem, p. 115. Texto original: «Døden teppet er faldet for Virkelighedens Skueplads (...), saa ere de ogsaa alle Eet, de ere Mennesker, og ere alle det, de væsentligen vare, hvad Du ikke saae paa Grund af Forskjelligheden, Du saae, de ere Mennesker» (KG, 97). 
muestra indiferencia y te ha dado la espalda, o bien mira hacia otro lado para amar a otro; amarlo tal y como lo ves, cuando te traiciona y reniega de ti» ${ }^{32}$.

El amor es una pura exigencia de la interioridad que no espera nada del amante, no se activa bajo una condición, sino que se da incondicionalmente al otro. No espera nada, ni aquel mínimo dispensado por la comprensión. El amor perfecto se expresa y se muestra sin condiciones. La incondicionalidad es, verdaderamente, lo que da fuerza y legitimidad al amor, lo que nos hace divinos. Un amor bajo condiciones es un amor que aún tiene que crecer y purificarse, que aún está demasiado aferrado a los resultados que de él se deriven, que aún es ajeno a la gratuidad. Actúa buscando resultados y estos resultados condicionan su potencia. «El amor — afirma Kierkegaard - no es una cualidad existente para sí, sino una cualidad en la que tú existes para los demás» ${ }^{33}$.

Es una cualidad (en Egenskab) que hace que tú seas para los demás ( $D u$ er for Andre). En esto consiste el descentramiento que propicia al amor. Al amar de veras, se deja de vivir centrado en el yo, se abandona la existencia autocéntrica, para vivir abierto al otro, expectante al otro, atento a sus necesidades. Existe para el otro, y, al hacerlo, se descentra.

Un ejemplo arquetípico de este descentramiento es el amor materno-filial. La madre cede un espacio de su ser al otro (el hijo), lo nutre y lo cuida. Su foco principal de preocupación es su desarrollo y para alcanzarlo, se olvida de sí.

Amar es un movimiento extático, la salida de uno mismo. Se deja de vivir centrado en sí mismo, pero no se deja de ser lo que es. Al contrario, en la medida en que se da al otro, más crece uno, más plenamente se convierte en lo que está llamado a ser. En el mismo instante en que uno sale de sí mismo (den gaaer ud af sig selv) (dirección hacia fuera), es en sí mismo (er den i sig selv) (dirección hacia adentro); y en el mismo instante en que uno es en sí mismo, sale de sí mismo, de tal manera que es extraversión y retorno al mismo tiempo. Uno no se pierde al salir de sí mismo, sino que expresa su esencia. Igualmente, el ser que se da libremente a los demás, no pierde su ser, sino que crece como ser, porque el ser crece en la medida en que se da.

Kierkegaard parte de la tesis de que el foco del amor es el corazón, mientras que el centro del pensamiento es la cabeza. El amor puro fluye de un corazón puro y un corazón puro es un corazón desligado, que no está encadenado a ningún objeto en concreto, ni aferrado a ningún sujeto en particular; que ama a todos sin hacer distinción.

El corazón puro es un corazón ligado a la Fuente última de su ser y Fundamento de toda su capacidad de amar. Es aquel lazo que, precisamente, le hace estar desligado de todos y el que le permite relativizar cualquier vínculo, también cualquier pérdida, porque sólo lo eterno puede dar esperanza y si falta lo eterno, solamente hay lugar para desesperación: «El amor —escribe el filósofo danés- es un asunto de la conciencia, y por tanto, no es un asunto del instinto y la inclinación, ni del sentimiento, ni un asunto del cálculo racional» ${ }^{34}$.

Es un asunto de conciencia (Samvittighedens Sag). No nace de una forma espontánea, ni es fruto de un acto primario. El amor inmediato va propiciado por una percepción

32 Ibídem, p. 115. Texto original: "Døden teppet er faldet for Virkelighedens Skueplads (...), saa ere de ogsaa alle Eet, de ere Mennesker, og ere alle det, de væsentligen vare, hvad Du ikke saae paa Grund af Forskjelligheden, Du saae, de ere Mennesker" (KG, 97).

${ }_{33}$ Ibídem, p. 270. Texto original: "Kjerlighed er ikke en forsigværende Egenskab, men en Egenskab, ved hviken eller i hvilken Du er for Andre" (KG, 23).

${ }_{34}$ Ibidem, p. 178. La cursiva es de Kierkegaard. Texto original: "Kjerlighed er Samvittighedens Sag, og er saaledes ikke Driftens og Tilbøielighedens, eller Følelsens Sag, eller Forstands-Beregningens Sag» (KG, 158). 
externa, por la sensualidad, por el gusto, por la simpatía o la afinidad. Su fundamento es exterior, mientras que el amor pleno fluye de la consciencia, y por tanto no es una sublimación del instinto ni tampoco una inclinación egocéntrica. Lejos del sentimentalismo falsamente romántico, Kierkegaard entiende el amor como una fuerza interior que trasciende las emociones, la sensibilidad.

En el sagrario de la consciencia, el ser humano tiene experiencia de la Fuente originaria del amor. Solamente si es receptivo a esta llamada interior puede amar verdaderamente y trascender al amor de predilección que está ligado a los afectos y a los desafectos.

El amor trasciende la lógica del cálculo. No amo al otro pensando qué puedo obtener, mirando los beneficios que me puede reportar. Lo amo porque me siento llamado a amarlo, incluso aunque tan sólo me reporte sufrimientos y preocupaciones.

El amor pleno no es una estrategia racional que busca la compensación entre costos y beneficios. Obedece a la lógica del don, y por tanto, su dinamismo es la gratuidad. En este sentido, no espera nada, no atiende a los resultados. El amor, tal y como lo concibe Kierkegaard, trasciende la racionalidad instrumental; pero no, por ello, es irracional, ciego o absurdo. Obedece a otra racionalidad, se ejercita a partir de una inteligencia cordial que no se puede captar ni entender desde la mera razón instrumental. Aun así, el ser humano, tal como dice Kierkegaard en el capítulo primero de la segunda serie de discursos, necesita saberse amado, experimentar la recepción del amor. Donación y receptividad constituyen los dos polos del amor. Kierkegaard escribe: «Maravilloso: Existe un yo y un tú, y ¡no existe un mío ni tuyo! Ya que, sin no hay un tú ni un yo, no hay amor, y con mío y tuyo tampoco hay amor; pero mío y tuyo (estos pronombres posesivos) están formados a partir de yo y tú, y por tanto, parecería que debería darse en todas las partes en las que hay yo y tú » ${ }^{35}$.

Si no hay un yo $(\mathrm{Jeg})$ y no hay un tú $(\mathrm{Du})$, distintos, singulares y separados, no hay amor, pero el amor transforma el posesivo, de tal manera que al amar, desaparece el posesivo de primera persona del singular (Mit) y el posesivo de segunda persona del singular (Dit).

El amor es una revolución, la más profunda de todas. Cuanto más profunda sea, más perfecto será el amor. Amar es estar fuera de sí, olvidarse de uno mismo. Trasciende la justicia conmutativa, pero también la justicia distributiva. Quien ama, da, pero no da pensando en lo que se le ha dado antes; no da para compensar lo que ha recibido; ni esperando recibir lo mismo que ha dado. Da porque se siente llamado a dar, aunque dando lo pierda todo. Da porque el amor que late en su ser lo llama a darse, a superar la estrechez de la finitud y a ensanchar a su ser donante. El otro, al recibir el don, experimenta el deber de corresponder, pero el donante no sabe, en el acto de dar, si será o no correspondido. El amor trasciende la justicia, pero trascenderla no significa oponerse, ni contradecirla, sino abrir la relación humana a un estrato superior.

Siguiendo la Carta a los Romanos, subraya que el amor es la plenitud de la ley ${ }^{36}$. Al amar, no se pone en crisis la ley, sino que se trasciende, Quien ama no se limita a cumplir la ley establecida; va más allá, se eleva hacia los máximos, dejando atrás los mínimos legales exigibles. El amor no es, de ninguna forma, un subterfugio para escaparse

35 Ibídem, p. 321. Texto original: «Forunderligt, der et et Du og et Jeg, or der er intet Mit og Dit! Thi uden Du og uden Jeg ingen Kjerlighed, og med Mit og Dit ingen Kjerlighed; men Mit og Dit (disse Eiendoms-Stedord) er jo dannet af Du og Jeg, og synes altsaa at maatte være overalt, hvor der er Du og $\mathrm{Jeg}$ (KG, 69).

36 Cf. Rm 13, 10. 
de la ley, no es ninguna indulgencia, una forma de exigir dispensa. El amor va más allá de la ley, la trasciende, la lleva a su máxima plenitud. Lo que no exige el ordenamiento jurídico, lo exige el amor en la consciencia.

«El amor — sentencia Kierkegaard - no busca lo que es suyo; ya que buscar lo que es suyo no es otra cosa que amor de sí, egoísmo » ${ }^{37}$. El amor borra la diferencia entre lo que es propio y lo que es del otro. Desaparece el posesivo de primera persona del singular, porque también se esfuma la pulsión posesiva. La confusión o trastorno de identidades comporta la generación de un «nosotros» único, pero sin disolver la identidad del yo ni la identidad del tú.

En este sentido, el amor trasciende a la justicia, porque si la justicia consiste en dar a cada uno lo que es suyo, el amor supera el plano de la posesión, y quien da, no da pensando cuánto hay que dar a cada uno. En el acto de justicia, cada uno exige lo que le corresponde, ni más ni menos. La justicia establece y divide, determina qué es lo que cada uno tiene derecho a denominar lo suyo, y juzga y castiga a quien se ha apropiado de lo que no era suyo.

El amor es, en este sentido, un acontecimiento que va más allá de los cálculos de justicia, de nivelación de fuerzas y dones. Kierkegaard entiende que es el acontecimiento más grande de todos, el más alegre, el más extraño. El verdadero milagro es la gratuidad, la acción pura, desinteresada. Cuando irrumpe el amor eterno, la justicia empalidece; no es negada, sino trascendida.

Cuando el amor pleno tiene lugar en el mundo, se suscita una verdadera metamorfosis. La justicia conmutativa es superada y aquella obra que aparece es, sencillamente, paradójica, porque choca violentamente con los parámetros de la razón calculadora. Cuando una persona se siente amada generosamente, sin merecerlo, no sabe cómo devolverlo, no sabe por qué ha vivido esta sobreabundancia y esto la remueve profundamente. Es una discontinuidad, un signo de la eternidad en el mundo.

La narración que ilustra bellamente esta sobreabundancia del amor, la lógica del don que trasciende la lógica del cálculo es la parábola del hijo pródigo. Es acogido incondicionalmente. No es tratado con justicia, no recibe lo que ha hecho, no se le paga con la misma moneda. El padre no le recrimina lo que ha hecho, porque el amor que le mueve lo perdona todo y lo soporta todo.

Esta salida de uno mismo hacia el otro o movimiento extático, está ya presente en el enamoramiento. Kierkegaard, siguiendo la idea platónica, lo concibe como un sentirse fuera de sí, como un entusiasmo vivificador, que genera confusión, dado que para el enamorado ya no existe una diferencia entre lo mío y lo suyo.

En el acto del amor, el yo se libera del ego y se abre al tú, y al hacerlo no entiende sus talentos como propiedades suyas, sino como dones que ha recibido para darlos a los demás siguiendo la lógica del amor que fluye del fondo de su ser. ${ }^{38} \mathrm{Al}$ abrirse al tú se

37 Ibídem, p. 319. Texto original: «Nej, Kjerlighed søger ikke sit Eget, thi at søge sit Eget, er jo netop Selvskjerlighed, Egenkjerlighed, Selvsyge» (KG, 67).

38 La liberación del ego comporta un movimiento de resignación infinita. Es esta resignación la que hace posible la transición del estadio ético al estadio religioso. Así lo expresa David Roberts, "The Integrity of Evil. Kierkegaard on the Actualization of Human Evil», en Philosophy Today 54 (2010) 371: "Infinite resignation is not only dying to the world and its contents, but also dying to one's self, or one's self-centered attempts at self-mastery. This is no longer to have the world revolve around oneself —even if by oneself one means one's ethical duties. It is an opening to the otherness of the other, though in a still abstract and completly internal manner. Infinite resignation is the creation of a pure openness, which is not filled with this or that, but with otherness as a kind of abyss; it is through this openness that one's existence is transformed». 
construye la comunidad, pero es una comunidad de amor cuando el nosotros resultante se abre también fuera de sí mismo y se da fuera de la elipsis entre el yo y el tú.

De esta forma, pues, se crea un nosotros, porque se crea una comunión sólida que no se basa en las predilecciones ni en las circunstancias puntuales del instante; se fundamenta en aquella secreta Fuente que exige amar al prójimo como a uno mismo.

El amor no es un pacto ni un contrato social, tampoco el resultado de una negociación entre dos entidades que luchan por su autonomía personal. Menos aún una forma de sumisión o de heteronomía. La relación de poder es incompatible con la vinculación amorosa. El amor, tal y como deriva de estos textos kierkegaardianos, es aquella potencia que hace trascender al yo, para llevar a ser un yo distinto, movido por aquella Fuerza que lo trasciende, para convertirse en un yo teológico (theologiske selvet) ${ }^{39}$, un yo liberado de la tendencia posesiva y cimentado en aquella Fuerza interior que le abre a los demás gratuitamente.

Søren Kierkegaard utiliza tres palabras para referirse al amor autocéntrico: Selvskjerlighed, Egenkjerlighed y Selvsyge. En estas tres palabras, utiliza el prefijo danés selv que significa uno mismo, análogo al autos griego. El foco de atención de este amor es uno mismo, por esto es endogámico y solipsista. Contra este amor autoreferenciado plantea el amor como salida hacia el otro, abandono confiado y entrega al otro.

Finalmente, el amor es, esencialmente, entrega. En la práctica del amor auténtico, se ama al otro en su peculiaridad, de tal manera que se está dispuesto a hacer cualquier sacrificio para que el otro sea aquello que está llamado a ser. Quien ama así, no busca su beneficio, su recompensa material o espiritual, sino dar de tal forma que el don recibido parezca que sea propiedad del otro. No recrimina lo que ha dado, no exige que se le devuelva, ni humilla al otro para hacerle ver que todo lo que tiene le ha sido dado. Da y hace ver que el don es propiedad del otro, cuando, de hecho, no le pertenece. Aun así, como Kierkegaard recuerda en el capítulo VII de Las Obras del Amor, la obra del amor puede realizarse, incluso, si uno no puede donar nada o no puede hacer nada.

Universitat Ramon Llull, Barcelona

FRANCESC TORRALBA

rancesctr@blanquerna.url.edu

[Artículo aprobado para publicación en noviembre de 2013].

39 Sobre esta metamorfosis, véase la magnífica Tesis Doctoral de CÀnovas Miranda, J. C., Culpa, amor i mort, cruïlles existencials en la transformació del "si mateix humà» en "si mateix teològic», Departament de Filosofia, Universitat de les Illes Balears, 2010. Defendida el 10 de enero de 2011 en la Universitat de les Illes Balears bajo la dirección de Gabriel Amengual. 